\title{
TI.66.1
}

\section{Shibboleth Architecture Protocols and Profiles}

- PDF: draft-mace-shibboleth-arch-protocols-latest.pdf

- Text: draft-mace-shibboleth-arch-protocols-latest.txt

\section{More Information}

\begin{tabular}{|c|c|}
\hline Repository ID & TI.66.1 \\
\hline Persistent URL & http://doi.org/10.26869/TI.66.1 \\
\hline Title & Shibboleth Architecture Protocols and Profiles \\
\hline Authors & Scott Cantor, Steven Carmody, Marlena Erdos, Keith Hazelton, Walter Hoehn, RL "Bob" Morgan, Tom Scavo, David Wasley \\
\hline Sponsor & MACE \\
\hline \multicolumn{2}{|l|}{ Review } \\
\hline Status & Legacy \\
\hline Publish Date & February 28, 2005 \\
\hline DOI & 10.26869/TI.66.1 \\
\hline \multicolumn{2}{|l|}{ Signature } \\
\hline Deprecated & Yes \\
\hline \multicolumn{2}{|l|}{ Future Review } \\
\hline \multicolumn{2}{|l|}{ Supersedes } \\
\hline Format & PDF, Text \\
\hline \multicolumn{2}{|l|}{ Related Docs } \\
\hline \multicolumn{2}{|c|}{ Development Location } \\
\hline \multicolumn{2}{|l|}{ IP Framework } \\
\hline Subject Tags & middlewarerescue \\
\hline Notes & \\
\hline
\end{tabular}

